\title{
Cryosurgery of genital warts in cases in which podophyllin treatment failed or was contraindicated
}

\author{
A. K. GHOSH \\ From Liverpool Royal Infirmary
}

SUMMARY A total of 56 cases with warts in which podophyllin treatment was either contraindicated or a failure, were treated with nitrous oxide using a Keymed 500 cryosurgical appliance. Forty-three patients who completed treatment were followed-up for three months. Thirty-seven of these had received applications of podophyllin twice weekly for an average period of three months before cryosurgery. The remaining cases in whom podophyllin was considered to be contraindicated included five with vulval warts (two were pregnant, two were bronchial asthmatics taking oral prednisolone, and one was taking oral clomiphene citrate), and a diabetic patient with penile warts. Thirty-two were cured and 11 relapsed. The latter were re-treated at the end of the follow-up period with two freezing cycles of 45 seconds at an interval of 30 minutes. Seven were cured and the remaining four men who failed to respond belonged to the podophyllin-resistant group and included three with meatal warts and one homosexual with anogenital warts. Cryosurgery gave a cumulative success rate of $91 \%$. A single freezing cycle was free from complications but a double freezing cycle was often followed by severe local reaction.

\section{Introduction}

Genital warts have received scant attention until recently. Oriel (1971) described the natural history and epidemiology of genital warts and emphasised that they could be sexually transmitted.

The number of patients presenting with genital warts at Sexually Transmitted Disease (STD) clinics has increased in recent years (Department of Health and Social Security, 1976). The legally defined venereal diseases-namely, syphilis $(1.03 \%)$, gonorrhoea $(19.43 \%)$, and chancroid $(0.01 \%)$ constitute a fraction of the workload in STD clinics throughout Great Britain, while non-specific urethritis $(24 \%)$, candidiasis $(8.68 \%)$, trichomoniasis $(5.42 \%)$, and genital warts $(5 \cdot 34 \%)$ form most of it. The number of patients (male and female) with genital warts was 13730 in 1971 and 18733 in 1974. The total number with this condition attending the clinic at the Liverpool Royal Infirmary was 125 in 1971, 325 in 1974, and 361 in 1975. Besides this recent increase, treatment of the warts is often a problem.

Address for reprints: Dr A. K. Ghosh, Liverpool Royal Infirmary, Pembroke Place, Liverpool L3 5PU

Received for publication 9 July 1976
Resistance of genital warts to podophyllin is now common and their management presents a challenge to the venereologist in a busy STD clinic.

In 1974 the mean attendance made by a male patient with warts at the STD clinic at Liverpool Royal Infirmary for podophyllin treatment was eight compared with four visits by patients with non-specific urethritis and gonococcal urethritis. While an insignificant number of patients with gonococcal urethritis and $11 \%$ of the patients with non-specific urethritis had relapses after treatment, the figure in the case of genital warts was over $30 \%$. Clearly this high relapse rate adds to the workload.

There are still gaps in our knowledge on the biology of the wart virus. No specific anti-viral agent which eradicates warts is yet available and there is no immunizing agent to prevent their occurrence. Topical treatment is still the only available method, but one with lasting effect is desirable. Cryosurgery has been successfully tried in the treatment of genital warts (Brooks and Heldford, 1971; Ostergard and Townsend, 1969) and appears to be a useful alternative for patients who fail to respond to podophyllin or for those in whom podophyllin is contraindicated. In this paper the role of cryosurgery in the management of such cases is reported. 
Method and material

A separate male and female Wart Clinic, each held once a week, was started in the Department of Venereology of the Liverpool Royal Infirmary for this study. A Keymed 500 cryosurgical appliance with a condyloma probe, using nitrous oxide as the cryogen, was used. No local anaesthesia or premedication was used. Each wart was individually treated once for 45 seconds of a single freezing cycle. The number of warts determined the number of sittings. In most cases cryo treatment was completed in a single session and no case required more than three sittings which were at weekly intervals. Patients were followed-up for three months. Those who failed to respond to a single freezing at the end of the follow-up were re-treated with double freezing (two applications of 45 seconds at an interval of approximately 30 minutes) and kept under observation for a further period of three months.

The development of a successful cryolesion depends on the boiling point of the cryogen in use, the size of the cryoprobe, the amount of the tissue to be frozen, and the duration of the actual freezing cycle (Zacarian and Adham, 1967; Gill et al., 1970). The boiling point of the nitrous oxide is $-89^{\circ} \mathrm{C}$. This provides a working temperature of about $-70^{\circ} \mathrm{C}$ at the tip of the probe which, if left on living tissue for 45 seconds, will rapidly lower the cellular temperature to between $-20^{\circ} \mathrm{C}$ and $-25^{\circ} \mathrm{C}$. The cells subjected to this range of subzero temperatures will be frozen and undergo a sequence of physical and chemical changes (Lovelock, 1957; Mazur, 1965; Farrant and Morris, 1973). The frozen tissue looks like a hard ice ball near the completion of the treatment with cryogen (Figs 1 and 2). As thawing progresses after stopping the cryogen, the lesions gradually become congested and oedematous leading to the formation of multiple blisters surrounding the cryolesion, resembling a second degree burn within the first six hours (Fig. 3). Necrosis takes place and the necrosed tissue sloughs off leaving a shallow ulcerated base by the end of a week (Figs 4 and 5). These ulcers heal rapidly within the following 10 to 12 days, usually without any local complication.

\section{Results}

Fifty-six patients were included in this study; 50 of whom had received podophyllin in various concentrations. The remaining patients were referred for cryosurgery as podophyllin in their cases was contraindicated. Forty-three (34 men and nine women) completed the three months' follow-up. Nine

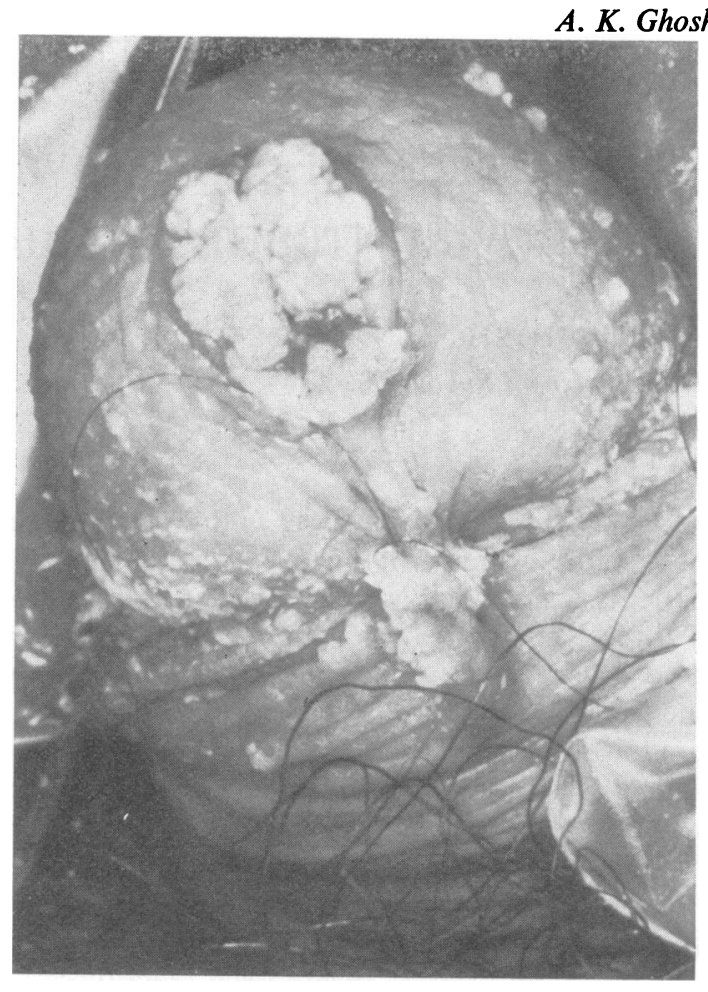

Fig. 1 Multiple meatal warts, previously treated unsuccessfully with podophyllin.

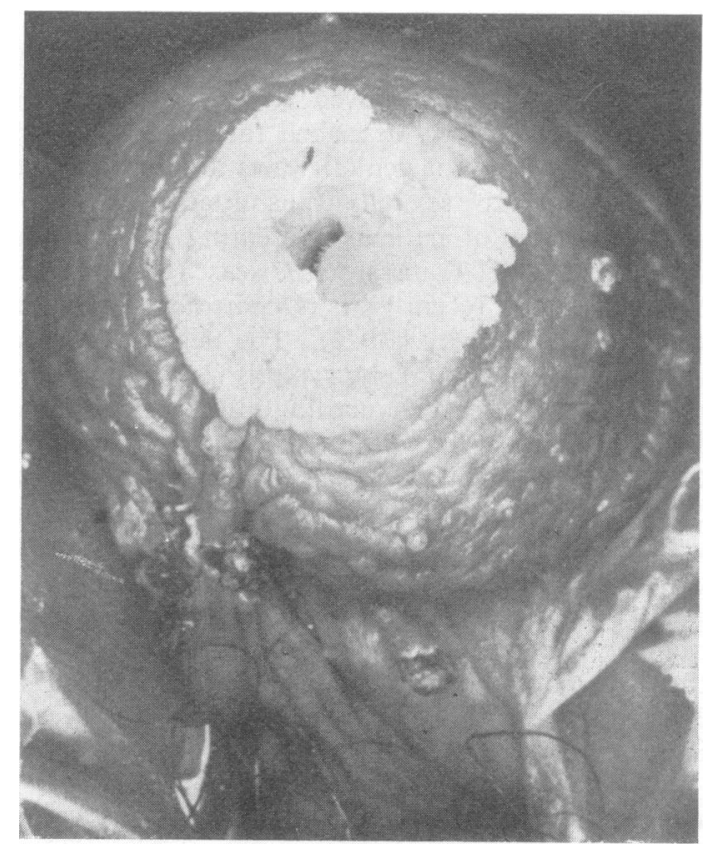

Fig. 2 Same patient 45 seconds after the application of cryo treatment showing ice-ball formation. 


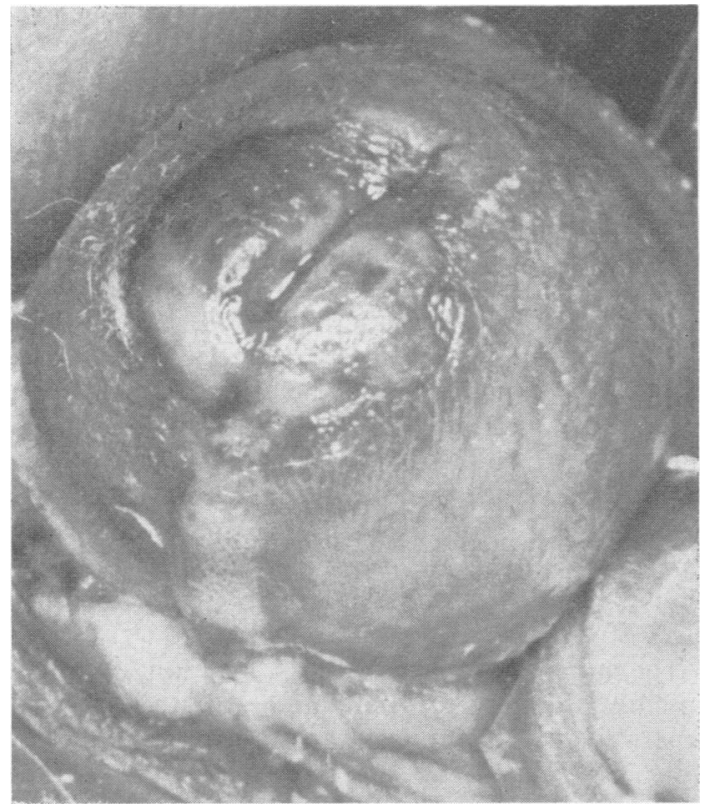

Fig. 3 Six hours after cryo treatment, showing oedema and multiple blisters similar to those of a second degree burn.

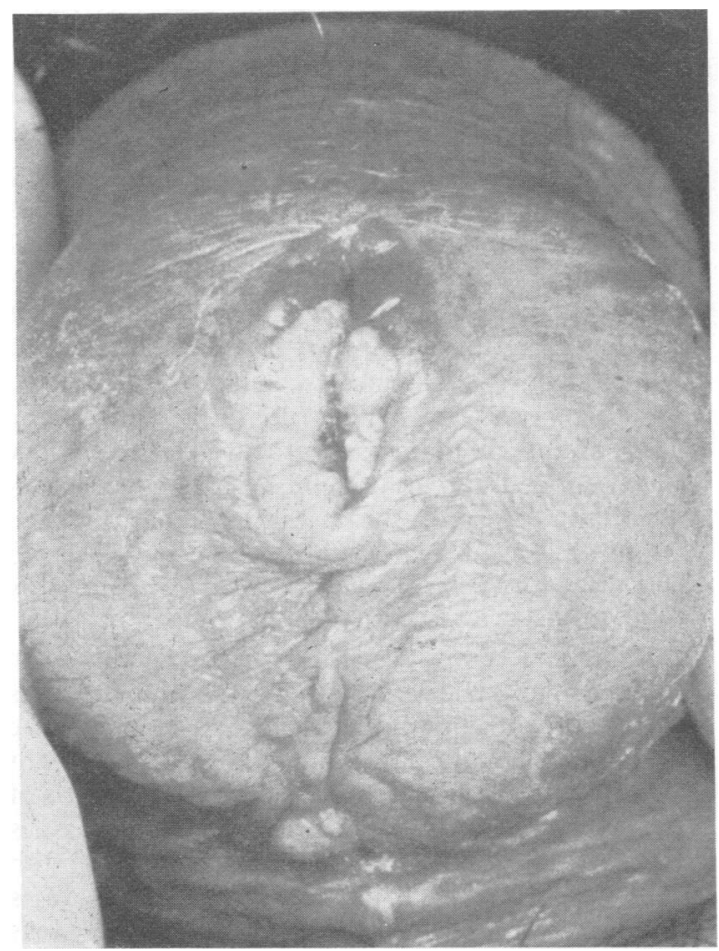

Fig. 448 hours after the cryo treatment, showing the reduction in size of the warts, due to central necrosis.

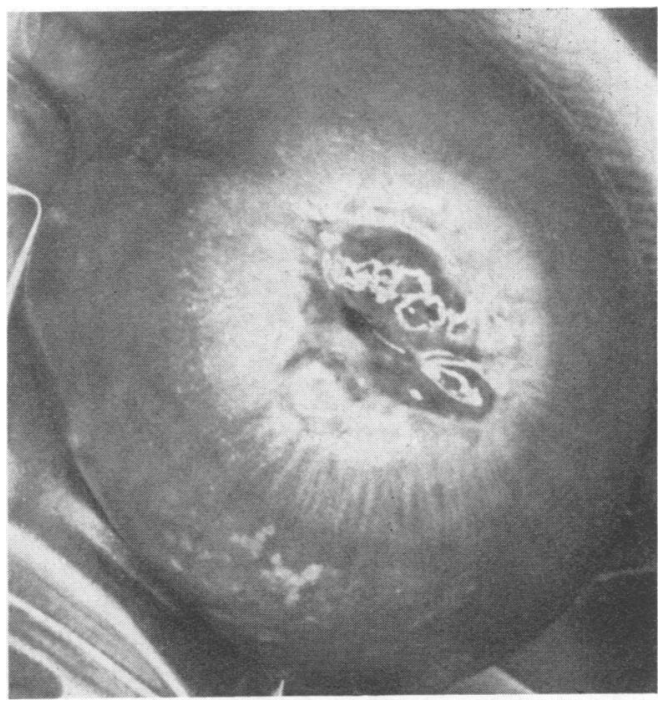

Fig. 5 Seven days after the cryo treatment when the necrosed tissue has sloughed off, leaving behind multiple shallow ulcers.

defaulted, and of the remaining four who did not complete treatment, three refused because of the burning pain during the thawing cycle, and the fourth was apparently frightened by the operating noise.

The results in the patients who completed follow-up will be presented in greater detail.

\section{MEATAL WARTS}

Of the 28 patients in this group (27 men and one woman) 20 were cured after a single application. Five of those in whom relapse occurred denied any sexual exposure. These eight cases who relapsed were re-treated with the double freezing-thaw cycle; five were cured and three failed to respond. Those who failed did not differ in any way from those who were cured.

\section{ANAL AND PERIANAL WARTS}

In this group there were six men, five of whom were homosexual, and three women. All the women and three of the six men responded after a single application. Three male homosexuals who failed to improve were re-treated with the double freezing cycle. Two were cured and the third failed to respond and had to undergo surgical treatment. All the cases in which failure occurred denied sexual exposure during the follow-up period. The patient who required surgery had very large and profuse warts. 
CASES IN WHICH PODOPHYLLIN WAS CONSIDERED TO BE CONTRAINDICATED

There were five women and one man in this group. Of the women, two were pregnant, two were bronchial asthmatics (twins) - both were taking oral prednisolone and one was taking oral clomiphene citrate-and all had vulval warts. The man, a young diabetic requiring insulin, had warts on the coronal sulcus and under the prepuce. They were all cured after a single freezing.

\section{COMPLICATIONS}

Single freezing for 45 seconds did not produce any local complication. However, all but one who received double freezing developed some degree of local complication. Seven of the eight patients with meatal warts who received double freezing developed considerable local oedema and a relatively large area of necrosis. However, all healed without scarring. Two developed paraphimosis and needed manual reduction. The three homosexuals with anal and perianal warts who received double freezing complained of intense pain while thawing took place followed by severe irritation, and later they developed perianal ulceration. One of these patients required systemic antibiotics for secondary infection which resulted in perianal scarring of no consequence.

All the cases in which relapse occurred developed warts on the original and/or new sites.

\section{Discussion}

Although the use of refrigerants is not new to STD clinics, it seems to be less commonly practised there than in dermatology clinics. Genital warts in the most difficult anatomical positions can conveniently be treated by cryosurgery and an effective cryolesion can be produced within a few minutes. Treatment with sensitizers like gluteraldehyde and dinitrochlorobenzene (DNCB) has proved encouraging for skin warts (Greenberg et al., 1973); however, their role in the genital warts is not yet clear. The natural course of genital warts is not established apart from their regression postpartum. The aim should be to eradicate the warts completely without local reaction or scarring. At the same time, attempts should be made to recognise, diagnose, and treat without delay any aggravating factor-such as, poor genital hygiene or vaginal discharge.

Migrating patients, regular defaulters, and patients with genital warts undergoing surgery for other lesions should be considered for treatment with cautery or cryosurgery. Podophyllin is less effective in plain warts and verruca vulgaris and its use is undesirable for intrameatal warts, intraurethral warts, and for vaginal and cervical warts. In all such cases and in others, including those resistant to podophyllin, giant condylomata acuminata producing obstruction, and in cases of doubtful diagnosis, podophyllin is better avoided. Skin lesions can become malignant after repeated applications of podopyllin. Podophyllin is known to produce polyneuritis and its application in pregnant women with genital warts is contraindicated because of its known teratogenic effect (Chamberlain et al., 1972). Podophyllin can induce severe local reaction in patients with autoimmune diseases, diabetes, and in those being treated with corticosteroids. Poor genital hygiene and failure to follow the instructions may partly be responsible; but severe local reaction was noted among some patients with nursing supervision. Apart from the above-mentioned conditions, podophyllin remains the first line of treatment for most cases of genital warts.

The number and type of warts, location, duration, possibly the age of the patient, and finally the experience of the physician are all important factors which will determine the type of treatment. The cryosurgical approach is valuable in eradicating stubborn genital warts. Cryolesions heal quickly without any complication, unlike treatment with cytotoxic chemicals. Cryosurgery needs no anaesthesia and the application of subzero temperature is speedy and painless. In certain cases-such as those having multiple giant warts and in the rare event of countless pinhead warts covering a large areathis procedure may be time-consuming but cytotoxic chemicals and sloughing agents are often undesirable. One patient noted the disappearance of warts from an untreated area after the first application of cryosurgery. Whether a specific antibody is formed against the genital wart tissue after cryogenic treatment which subsequently causes the untreated warts to regress, or whether this is a coincidental finding of the spontaneous autocure remains to be seen (Pyrhönen and Johansson, 1975). Cryosurgery is especially helpful in the cases of pregnant women with multiple giant warts with only a few weeks to their confinement. An area can be freed for episiotomy if needed during vaginal delivery.

The high success rate with cryogenic treatment in this particular series may be due to the previous applications of podophyllin which might have reduced the size and number of the warts, or might have removed the keratin layer from the surface of the warts, thus softening them. Soft moist tissues respond better to cryo treatment. With the exception of one woman, all the patients with meatal warts also had lesions elsewhere on the genitals. The warts on these other sites cleared with podophyllin before the cryogenic treatment, but the meatal warts per- 
sisted and appeared to be less sensitive to podophyllin. Besides the reduced adherence of podophyllin to the mucosal surface, excessive urethral secretion and urination may dilute the concentration of podophyllin applied or remove it completely from the surface. Cryosurgical treatment should be carried out earlier in such circumstances, possibly within the first week of attendance. The patient with anogenital warts who did not respond to cryo treatment had multiple and large warts covering a wide area of the anal verge and these were too large for outpatient cryosurgery. Warts tend to be big and multiple around the anal region and often require months of regular podophyllin. Cryo treatment offers the best alternative in these cases.

I am indebted to Dr O. P. Arya, Consultant Venereologist, for his help in preparing this paper; Dr Elisabeth Rees, Consultant Venereologist, for her encouragement and guidance; Dr C. D. Alergant, Senior Consultant Venereologist, for permitting me to study these cases during his clinical sessions; Dr E. H. Annels, Consultant Venereologist and Dr F. Lanceley, Consultant Venereologist, for allowing me to study their cases. I thank all the nursing staff for their help and co-operation and Mrs B. Pritchard, departmental secretary, for her care in typing this manuscript.

\section{References}

Brooks, P. G., and Heldford, A. J. (1971). Cryosurgery 'painless and effective'. $O B-G Y N$ Observer, October, p. 6.

Chamberlain, M. J., Reynolds, A.L., and Yeoman, W. B. (1972). Toxic effect of podophyllum application in pregnancy. British Medical Journal, 3, 391-392.

Department of Health and Social Security (1976). CMOs Report, p. 77. HMSO: London.

Farrant, J., and Morris, G. J. (1973). Thermal shock and dilution shock as the causes of freezing injury. Cryobiology, 10, 134-140.

Gill, W., Da Costa, J., and Fraser, J. (1970). The control and predictability of a cryolesion. Cryobiology, 6, 347-353.

Greenberg, J. H., Smith, L., and Katz, R. M. (1973). Verrucae vulgaris rejection. A preliminary study of contact dermatitis and cellular immunity response. Archives of Dermatology, 107, 580-582.

Lovelock, J. E. (1957). The denaturation of lipid-protein complexes as a cause of damage by freezing. Proceedings of the Royal Society, Series $B, 147,427-433$.

Mazur, P. (1965). Causes of injury in frozen and thawed cells. Federation Proceedings, 24, 175-182.

Oriel, J. D. (1971). Natural history of genital warts. British Journal of Venereal Diseases, 47, 1-13.

Ostergard, D. R., and Townsend, D. E. (1969). The treatment of vulval condyloma acuminata by cryosurgery. Cryobiology, 5, $340-342$.

Pyrhönen, S., and Johansson, E. (1975). Regression of warts. An immunological study. Lancet, 1, 592-595.

Zacarian, S. A., and Adham, M. L. (1967). Cryogenic temperature studies of human skin. Temperature recordings at two millimeter human skin depth following application with liquid nitrogen. Journal of Investigative Dermatology, 48, 7-10. 